\title{
Growth of silicon carbide bulk crystals by physical vapor transport method and modeling efforts in the process optimization
}

\author{
Qi-Sheng Chen ${ }^{\mathrm{a}, \mathrm{c}, *}$, Jing Lu ${ }^{\mathrm{a}}$, Zi-Bing Zhang ${ }^{\mathrm{a}}$, Guo-Dan Wei ${ }^{\mathrm{b}}$, Vish Prasad ${ }^{\mathrm{c}}$ \\ ${ }^{a}$ Institute of Mechanics, Chinese Academy of Sciences, 15 Bei Si Huan Xi Road, Beijing 100080, China \\ ${ }^{\mathrm{b}}$ Department of Materials Science Engineering, Tsinghua University, Beijing 100084, China \\ ${ }^{\mathrm{c}}$ Department of Mechanical and Materials Engineering, Florida International University, 10555 W Flagler Street, Miami, FL 33174, USA
}

Available online 26 May 2006

\begin{abstract}
Silicon carbide bulk crystals were grown in an induction-heating furnace using the physical vapor transport method. Crystal growth modeling was performed to obtain the required inert gas pressure and temperatures for sufficiently large growth rates. The SiC crystals were expanded by designing a growth chamber having a positive temperature gradient along the growth interface. The obtained $6 \mathrm{H}-\mathrm{SiC}$ crystals were cut into wafers and characterized by Raman scattering spectroscopy and X-ray diffraction, and the results showed that most parts of the crystals had good crystallographic structures.
\end{abstract}

(C) 2006 Elsevier B.V. All rights reserved.

PACS: 81.05.Hd; 81.10.Aj; 81.10.Bk; 87.64.Gb; 87.64.Je

Keywords: A1. Growth models; A1. X-ray diffraction; A2. Growth from vapor; A2. Single crystal growth; B1. Silicon carbide

\section{Introduction}

Wide-bandgap silicon carbide $(\mathrm{SiC})$ substrates are needed for fabrication of electronic and optoelectronic devices and circuits that can function under high-temperature, high-power, high-frequency and intense-radiation conditions [1]. The physical vapor transport (PVT) method has been widely used to grow $\mathrm{SiC}$ bulk crystals since the 1970s [2], and the diameter of $\mathrm{SiC}$ single crystals grown by this method has increased from 50 to $100 \mathrm{~mm}$ [3].

Defects such as micropipes and dislocations in the crystal are main obstacles for its applications. The dislocation generation and propagation is related to the thermodynamics, kinetics and technologies used. Since in situ measurements of temperature, flow velocity, species concentration and growth rate inside the growth chamber are extremely difficult, physics-based process modeling is a powerful tool by which one can develop a better under-

\footnotetext{
${ }^{*}$ Corresponding author. Institute of Mechnics, Chinese Academy of Sciences, 15 Bei Si Huan Xi Road, Beijing 100080, China.

Tel.: + 861062564199 ; fax: + 861062615524 .

E-mail address: qschen@imech.ac.cn (Q.-S. Chen).
}

standing of the transport phenomena and physics in a $\mathrm{SiC}$ growth system. The process modeling tool can also help in optimizing the growth process.

\section{Experiments}

A $\mathrm{SiC}$ growth system was set up in our lab, which consists of a radio-frequency (RF) copper coil, quartz tube, carbon insulation, graphite susceptor, crucible and other components. The graphite crucible is filled with a $\mathrm{SiC}$ powder charge, and a $\mathrm{SiC}$ seed is placed on the bottom of the crucible lid. An RF induction power supply is used to generate heat in the graphite susceptor, and the $\mathrm{SiC}$ powder charge is then heated by the crucible. A mass flow meter was used to control the inert-gas pressure in the growth chamber. Two pyrometers were used to measure temperatures at the top and bottom of the crucible.

High-quality $6 \mathrm{H}-\mathrm{SiC}$ crystals were grown according to the procedures in Ref. [1]. The growth process consists of following steps. In the vacuum degassing stage, a low gas pressure $\left(10^{-3} \mathrm{~Pa}\right)$ and an evacuation temperature $(1073 \mathrm{~K}<T<1273 \mathrm{~K})$ are applied to reduce the background nitrogen contamination; in the preheating stage, 
temperature is gradually increased in a high-purity argon environment of $1 \mathrm{~atm}$ to the growth temperature and stabilized to achieve an optimum $\Delta T$ between the source and the seed; in the growth stage, a programmed argon pressure reduction to $10 \mathrm{~Pa}<p<2.66 \times 10^{4} \mathrm{~Pa}$ is used to achieve low-defect nucleation and uniform epitaxy on the oriented seed crystal, and boule growth begins; in the cooling stage, the temperature is gradually reduced after the growth is completed. The difference of temperature between the charge and seed during the growth stage depends on the system configuration, and is considered critical to the crystal quality.

\section{Numerical simulation}

Crystal growth modeling has been performed to obtain the required inert-gas pressure and temperatures for sufficiently large growth rates. Modeling is based on the PVT growth theory first proposed in Ref. [4], which assumes that the growth rate is proportional to the supersaturation of $\mathrm{SiC}$ species near the growth interface. The predicted growth rates at growth pressures of $8-12 \mathrm{kPa}$ are shown in Fig. 1, where the growth rate has an Arrhenius-like dependence on the bottom-hole temperature for growth pressures of 8,10 and $12 \mathrm{kPa}$.

Temperature distributions in the growing crystals were obtained [5] and the seed temperature is estimated by numerical simulations as $2671 \mathrm{~K}$ for the induction frequency of $8 \mathrm{kHz}$ and current of $1400 \mathrm{~A}$ in the induction coil, while the bottom-hole temperature is $2540 \mathrm{~K}$ and growth rate is $0.85 \mathrm{~mm} / \mathrm{h}$ for the growth pressure of $10 \mathrm{kPa}$ [5]. The temperature gradients in the growing crystals in the axial and radial directions are about 20 and $6 \mathrm{~K} / \mathrm{cm}$,

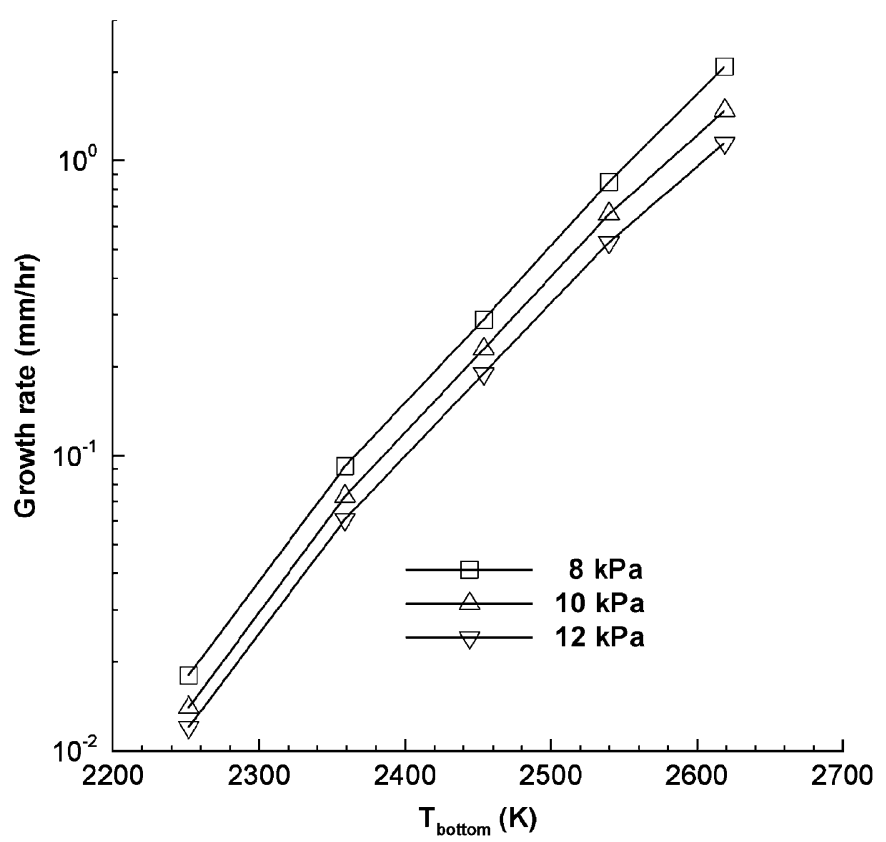

Fig. 1. Simulated growth rate versus the bottom-hole temperature. respectively [5]. We only simulated the temperature distributions and growth rates for several currents in the induction coil (see symbols in Fig. 1); one can estimate the temperatures and growth rates for other currents in the coil by the interpolation method. The thermal pack in the growth system was optimized using the numerical simulations to achieve the required seed temperature and temperature gradients. Without modeling and numerical simulation, optimization of the thermal pack would be tedious or even unsuccessful if resources were limited.

\section{Results and discussions}

Enlargement of the crystals was performed by designing a growth chamber having a positive temperature gradient along the growth interface. $6 \mathrm{H}$ polytype $\mathrm{SiC}$ crystal of $50 \mathrm{~mm}$ diameter and $25 \mathrm{~mm}$ height was grown at a rate of $1.2 \mathrm{~mm} / \mathrm{h}$ and pressure of $10 \mathrm{kPa}$ using an expansion technique (Fig. 2). The growth surface was the silicon face

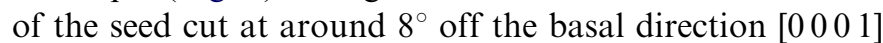

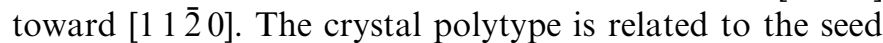
temperature and other conditions, and the seed temperature in the current case falls in the temperature range of the $6 \mathrm{H}$ polytype growth. The crystals were growing in the direction parallel to the maximum temperature gradient in the current case. A positive radial temperature gradient at the seed surface can initiate an outward growth and depress the polytype growth. Lower temperature at the center of the seed can ensure a higher growth rate at the seed than that at the graphite lid, since the supersaturation of the vapor species is higher at the seed.

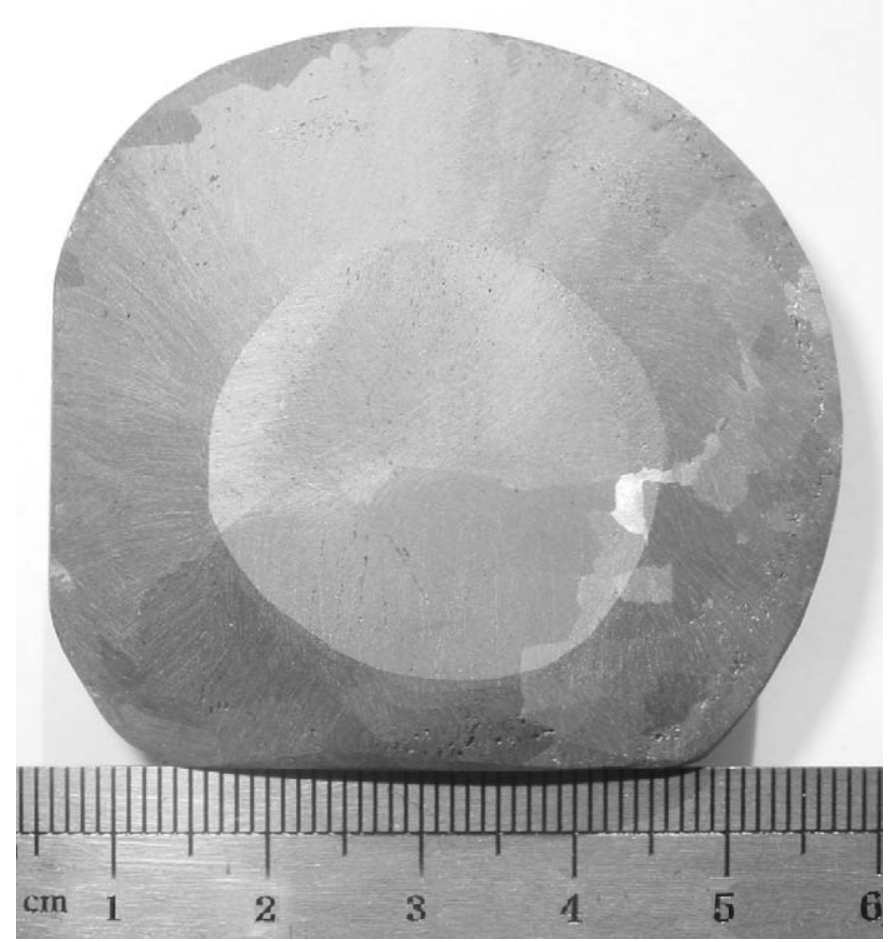

Fig. 2. $6 \mathrm{H}-\mathrm{SiC}$ bulk crystal. 


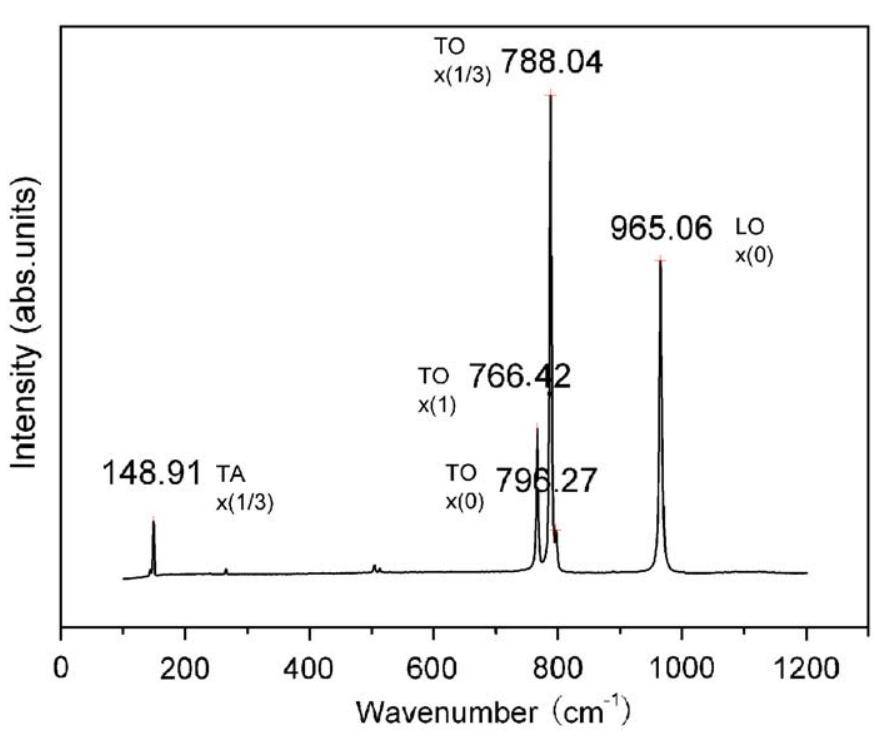

Fig. 3. Raman spectra taken on the $6 \mathrm{H}-\mathrm{SiC}$ crystal.

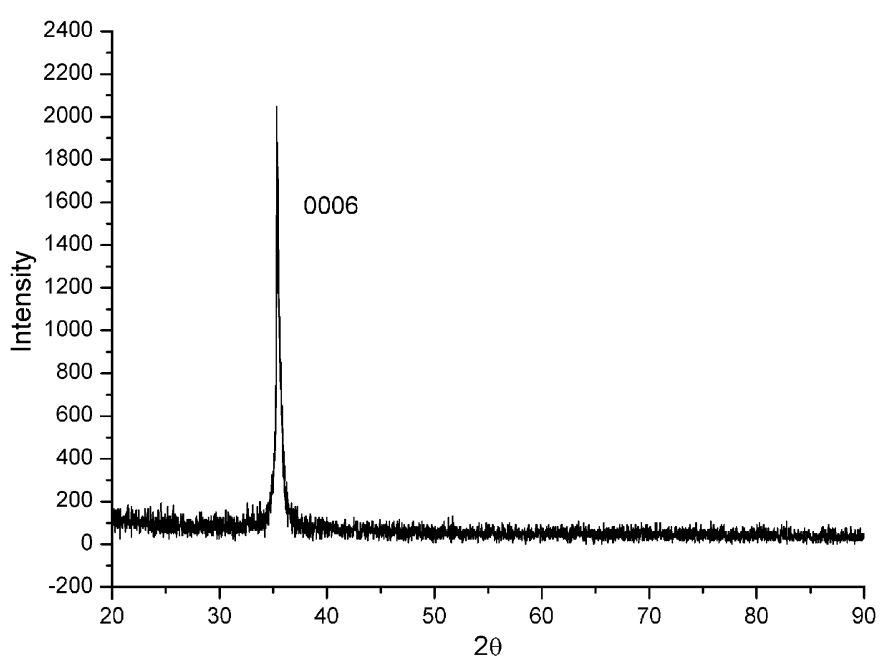

Fig. 4. XRD profile taken on a $6 \mathrm{H}-\mathrm{SiC}$ wafer of 1 -in diameter.

The bulk crystals were sliced into wafers perpendicular to the growth direction ( $8^{\circ}$ off-axis). The wafers were characterized using Raman scattering spectroscopy on a Renishaw RM2000 Microscopic Confocal Raman Spectrometer with an excitation wavelength of $633 \mathrm{~nm}$. Fig. 3 shows the typical Raman spectra. Two predominant sharp lines of 788.04 and $965.06 \mathrm{~cm}^{-1}$ can be clearly observed in Fig. 3 and are indexed to $6 \mathrm{H}-\mathrm{SiC}$ (they were 789 and $965 \mathrm{~cm}^{-1}$ in Ref. [6], respectively). The former characterizes the optic mode $x=\frac{1}{3}$ of $6 \mathrm{H}-\mathrm{SiC}$ in the TO branch and the latter corresponds to the optic mode $(x=0)$ in the LO branch. The TO $(x=1)$ band was observed at $766.42 \mathrm{~cm}^{-1}$ (it was $767 \mathrm{~cm}^{-1}$ in Ref. [6]). The Raman scattering spectra were also taken at other points and almost no new scattering peaks other than those in Fig. 3 were visible. This further confirms that no other defects such as $4 \mathrm{H}-\mathrm{SiC}$ are present in the $\mathrm{SiC}$ crystals.

XRD was performed on a $\mathrm{SiC}$ wafer of 1 in diameter using a wide-angle X-ray diffractometer (Rigaku,

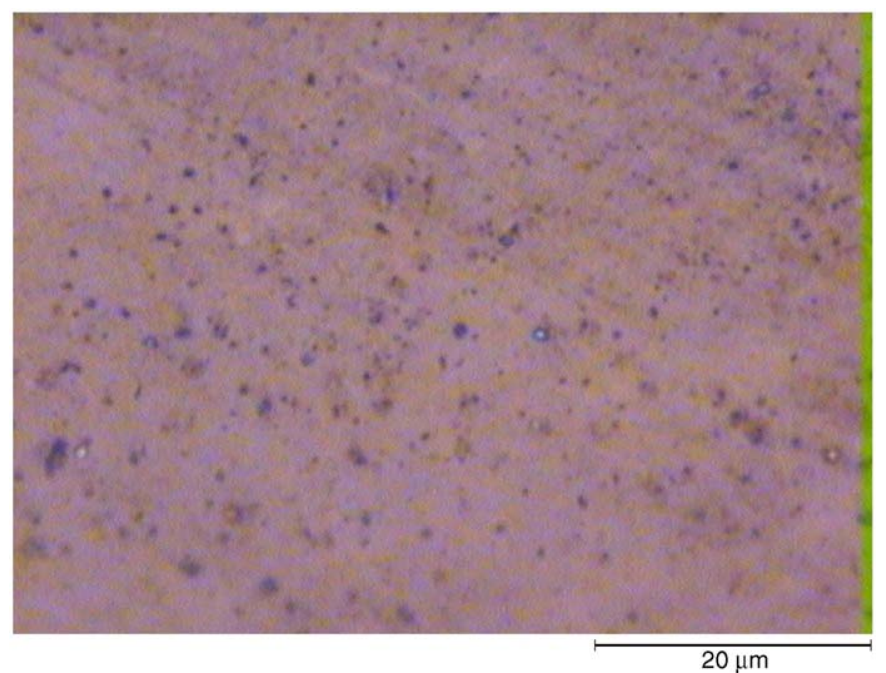

Fig. 5. Etch pits observed by an optical microscope.

RINT2000) with a $\mathrm{Cu} \mathrm{K} \alpha$ source $(40 \mathrm{kV}, 120 \mathrm{~mA})$. The XRD profile showed only one peak indexed to the $6 \mathrm{H}$ polytype (Fig. 4), indicating that most of the wafer exhibited good crystallographic structures. However, Xray topography is necessary to reveal the crystallographic uniformity and perfection of the wafer [7] and will be performed in the future.

$\mathrm{SiC}$ samples were etched in the $\mathrm{KOH}$ melt at $500^{\circ} \mathrm{C}$ for $30 \mathrm{~min}$ to reveal micropipe and dislocation defects. Fig. 5 shows the etch pits observable by an optical microscope. Some pits with a diameter of less than $1 \mu \mathrm{m}$ were seen on the sample surface but we did not observe micropipes, whose diameters are usually in the range of $10-50 \mu \mathrm{m}$.

\section{Conclusions}

Silicon carbide bulk crystals were grown using the physical vapor transport (PVT) method. Crystal growth modeling was used to obtain the required inert-gas pressure and temperatures for sufficiently large growth rates. We expanded the crystals by designing a growth chamber which has a positive temperature gradient along the growth interface. The obtained $6 \mathrm{H}-\mathrm{SiC}$ crystals were cut into wafers and characterized by Raman scattering spectroscopy and X-ray diffraction, and the results showed that most parts of the crystals exhibited good crystallographic structures. The modeling and numerical simulations were used for optimization of the thermal pack and facilitated the growth of 2-in SiC crystals.

\section{Acknowledgments}

This work has been supported by the National Science Foundation of China (10472126) and the Knowledge Innovation Program of the Chinese Academy of Sciences. 


\section{References}

[1] Q.-S. Chen, V. Prasad, H. Zhang, M. Dudley, in: K. Byrappa, T. Ohachi (Eds.), Crystal Growth Technology, William Andrew, NY, Springer-Verlag, NY, 2003, pp. 233-269.

[2] Yu.M. Tairov, V.F. Tsvetkov, J. Crystal Growth 43 (1978) 209.

[3] D. Hobgood, M. Brady, W. Brixius, G. Fechko, R. Glass, D. Henshall, J. Jenny, R. Leonard, D. Malta, S.G. Müller, V. Tsvetkov, C. Carter Jr., Mater. Sci. Forum 338-342 (2000) 3.
[4] Q.-S. Chen, H. Zhang, V. Prasad, C.M. Balkas, N.K. Yushin, S. Wang, J. Crystal Growth 224 (2001) 101.

[5] Q.-S. Chen, P. Gao, W.R. Hu, J. Crystal Growth 266 (2004) 320.

[6] S. Nakashima, H. Harima, Phys. Status Solidi (a) 162 (1997) 39.

[7] W.M. Vetter, M. Dudley, J. Appl. Phys. 96 (2004) 348. 